\title{
DO EMPIRISMO À CIÊNCIA: A EVOLUÇÃO DO CONHECIMENTO DE ENFERMAGEM*
}

\author{
Margareth Angelo** \\ Hideko Takeuchi Forcella** \\ Ilza Marlene Kuae Fukuda**
}

ANGELO. M. et al. Do empirismo à ciência: a evoluçáo do conhecimento de Enfermagem.

Rev. Hec. Enf. USP, v.29, n.2, p.211-23, ago. 1995

As autoras apresentam neste artigo a perspectiva evolutiva da ciência da Enfermagem utilizando como suporte sua evolução histórica. São abordados alguns aspectos da História da Enfermagem, com a intenção de caracterizar as maneiras complexas com que as pessoas e idéias do passado influenciaram nosso presente. As autoras estabeleceram fases que nortearam o desenvolvimento da profissão e do profissional.

LTNTERMOS:Higtória da Enfermagem. Exercício da Enfermagem. Educação em Enfermagem.

\section{INTRODUÇÃO}

(Yiencia 6 um corpo organizado de achados de pesquisa e testes de teorias num campo especifico de conhecimento. E ao mesmo tempo um processo e um produto. () processo envolve a formulação de teorias que ao serem testadas levam ao produto da ciência o conhecimento do mundo empírico, ou seja, da realidade como te experienciada. E sobre este conhecimento, mais especificamente sobre a evolução do conhecimento de Enfermagem, que tratia este texto.

Para darmos uma perspectiva evolutiva do conhecimento, utilizaremos como suporte a evolução da enfermagem.

* Trabalho apresentado no 4" ENFTEC, 1994

** Enfermeira. Professor Doutor do Departamento de Enfermagem Materno-Infantil e Psiquiátrica da Escola de Enfermagem da Universidade de Sao Paulo. Coordenadora do Centro Histórico.

Cultural da Enfermagem lbero-Americana 
Apresentaremos, portanto, alguns aspectos da História da Enfermagem, no sentido de caracterizar as maneiras complexas com que as pessoas e as idéias do passado têm influenciado nosso presente.

Com o intuito de associar a história ao conhecimento de Enfermagem, estabelecemos uma divisão por fases que nortearão o desenvolvimento da profissão e do profissional.

\section{A EVOLUÇÃO DA ENFERMAGEM}

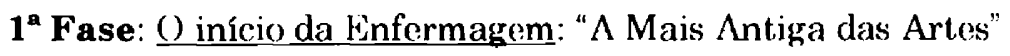

A Enfermagem surgiu como resposta intuitiva ao desejo de manter as pessoas saudáveis, como também de proporcionar conforto, cuidado e proteção ao doente. Esta resposta emanou de certas mulheres que provaram ser particularmente aptas em proporcionar um ambiente domestico saudavel, protegendo crianças e cuidando dos velhos e dos outros membros da família.

O cuidado é parte integral da vida humana e está contido nas raizes da história das mulheres, pois é ao redor do cuidado que a principal parte do destino das mulheres foi tecida. $A$ História da Enfermagem esempre referida como um episódio na história mulher.

Atraves da historia coube a mulher a responsabilidade de assegurar a continuidade da vida, lidando com os aspectos da vida relacionados a fertilidade, como cuidar dos recém-nascidos e de suas mães. e promover o crescimento e o desenvolvimento de crianças. Estando a morte ligada ao nascimento. as mulheres ocupavam-se dos doentes, mas não dos feridos pois esta era responsabilidade dos homens, que desenvolveram habilidades de tratar de lesões no corpo, e desenvolver atividades de caca e guerra que lhes caloia. Alem dos doentes cabia as mulheres cuidar dos velhos ou dos que estavam morrendo.

Ainda que estas fossem responsabilidades de todas as mulheres, algumas eram mais aptas do que outras para lidarem com as pessoas em suas crises pessoais e familiares.

Assim, o papel de "enfermeira" era assumido não por todas as mulheres, mas por aquelas que possuiam o real desejo e habilidade para cuidar.

Durante os periodos em que as mulheres estavam restritas ao lar por convenções sociais e suas ações limiladas à vida familiar, a enfermagem tam. bem pode ser caracterizada como sendo uma arte domestica. 
As primeiras enfermeiras eram generalistas independentes, que possuiam a liberdade de ação para serem tão criativas quanto suas habilidades intelectuais e pessoais permitissem. Embora suas respostas iniciais fossem intuitivas, o saber foi construído através da solução dos problemas emergentes e assim um corpo de conhecimentos gradualmente se desenvolveu e. expandiu.

Intuitivamente, a "enfermeira" buscava alimentos para compor uma dieta o mais balanceada possível para as pessoas que cuidava. Nesse processo, ela descobriu que certos alimentos provocavam reações como vômito e diarréia, e que também era possível extrair ingredientes medicinais de se. mentes, folhas, raizes, ervas. () conhecimento desenvolvido pela mulher sobre plantas e como utilizálas na alimentação e como recurso medicinal, formavam parte de seus métodos pessoais de cuidar.

() conhecimento que estas mulheres desenvolviam e acumulavam sobre saúde e experiências de vida, eram ensinados para outras mulheres que demonstravam motivação para cuidar. Assim, ainda que oralmente, a tradicão do cuidar foi expandida de geracão para geracão.

Olhando para o passado, vemos esta figura de mulher que alem de desempenhar os deveres de enfermeira desempenhava outros tambem como os de nutricionista, farmacêtica, assistente social e fisioterapeuta. E importante destacar que estas raizes culturais de cuidado relacionadas as práticas das mulheres. com seu conhecimento intuitivo (empírico). são origem não só da enfermagem. mas também de outras profissōes como a farmacologia e a agricultura. Assim era desenvolvida a enfermagem. até o advento de uma nova fase.

$2^{a}$ Fase: "D)a Enoca Sombria ao Renascimento"

A Enfermagem chamada medieval obteve do cristianismo sua mais importante contrilıuição solsetudo na Europa. Ainda que neste período de 1000 anos (de 476 - queda de Roma - a 1453 - queda de Constantinopla), os primeiros seculos sejam conhecidos como um período negro. podemos dizer que uma tradição mais ou menos contínua de aprendizagem foi se estabelecendo e tornando-se gradualmente forte.

$\Lambda$ contribuição do cristianismo para a enfermagem. é proveniente do conceito cristão de caridade. Em função desta obrigação. foram organizadas sociedades destinadas a amparar e vestir o pobre, educar as criancas polores. cuidar de orfãos. visitar os doentes, os velhos e cuidar de prisioneiros. 
$\Lambda$ caridade como virtude, encorajou milhares de homens e mulheres. inspirados no sacrifício, a dedicar suas vidas em assistir o próximo.

$\Lambda$ caridade foi institucionalizada quando a igreja designou os bispos para assumirem a responsabilidade pelos doentes, polores, viúvas, crianças e viajantes. Assim. casas de hospitalidade e de cuidado do doente surgiram, e o cuidado a estas pessoas era delegado aos diáconos, subdiáconos e diaconisas. onde os diáconos cuidavam dos homens da congregacão e as diaconisas das mulheres.

$\Lambda$ importância dos diáconos e diaconisas para a Enfermagem. nesta época, 6 que um grupo especifico de pessoas era destinado para desempe. nhar um papel particular que incluía o cuidado de doentes.

Esta foi uma etapa inicial no desenvolvimento da enfermagem. Os primeiros hospitais surgiram no início do seculo $4^{\circ}$, em resposta a necessidade de instituiçoes para o cuidado do polore. os xendochim ou casa de estrangeiros. pois. a palavra hospital surgiu no séc. 12.

Estes primeiros hospitais não eram destinados a todos os doentes mas àqueles que não podiam ser cuidados em suas próprias casas, como os viajant.es, pobres, orfãos e velhos. Pessoas de posição e provavelmente a maioria das pessoas medievais eram cuidadas em suas casas. por suas esposas. eseravos, pais ou filhos ou por mulheres que aluavam como enfermeiras nos lares. Muitos destes primeiros hospitais não possuiam médico para o atendimento. sendo a enfermagem, neste local considerada como sua principal função.

Neste período surgiram as ordens seculares de enfermagem. formadas por congregacões de monges e freiras.

Ao entrar para a ordem. as novicas aprendiam o cuidado o o servico eom o doente, alem de vários deveres religiesess que deveriam descempenhar. incluindo os votos de pobre\%a, obediencia o castidade.

() periodo de reforma ou renascimento (1500)-1880) foi crialivo especialmente para as artess o as ciências.

$\Lambda$ enfermagem. no entanto, não foi muito beneficiada pelas descobertas da epoea. Ao contrário. um dos primeiros efeitos do protestantismo fó retardar a enfermagem. já que instituições monástieas. incluindo hospitais a escolas, foram fechadas e muitas ordens. inclusive de enfermagem. foram dissolvidas.

Assim, a enfermagen constituida por uma ciência empírica de devocão ao doente. voltada particularmentee para o alivio da dor e do sofrimento. carente do conhecimento de como realizar este cuidado. vive um retrocesso importante (sece. 16-17).

Pequenos avanços em diresão a organização do ambiente e da assistên. cia ao doente, desapareceram juntamente com as ordens religiosas. 
$\Lambda$ decadência da assistência era evidenciada pelas precárias condições de higiene, conforto e cuidado do ambiente e das pessoas que prestavam os cuidados, caracterizadas como escórias da sociedade.

$O$ renascimento da enfermagem começou com a criação das damas e irmãs de caridade de São Vicente de Paula (séc. 16-17), na França. com a introdução de princípios modernos de enfermeiras visitadoras a de serviço social. Suas idéias de assistência enfatizavam o conceito de "ajudar as pessoas a se ajudarem".

As damas de caridade formada por mulheres da comunidade casadas ou viúvas, constituíram o primeiro trabalho de enfermagem comunitária que consistia em visitar o doente e torna-lo o mais confortavel possível. dandolhe alimento, preparando medicamentos e consolando aquele que estava morrendo ou sofrendo. No entanto. elas foram impedidas por seus maridose família de continuarem a desenvolver atividades que as retirasse de casa.

Surgiram. então, as irmãs de caridade que eram jovens solteiras que ingressavam no programa de São Vicente de Paula. Elas deveriam. como requisito. ser inteligentes e refinadas. alem de possuir genuíno in leresse pelo doente pobre.

Um programa educacional sistemático era oferecido. e consistia em desenvolver experiencia no hospital visitar as casas e cuidar dos doentes. () programa compreendia uma combinação de serviço social ao polire o cuidado ao doente.

Pode-se dizer que este o o início do reconhecimento da enformagem como uma das chamas para o bem-estar do doente.

\section{$3^{\mathbf{a}}$ Fase: "Uma Noval Profissão"}

A motivaçă das freiras diaconisas ou irmãs era primariamente roligiosa. Antes da enfermagem poder ser tolalmente aceita como uma ocupaçāo de valor. a importância das enfermeiras seculares tinha que ser reconhecida.

Esta era uma tarefa difícil. em parte pelo sistema hospitalar em si. mas. talvez, principalmente pela posição da mulher no seculo 19. Limbora no seculo 19, as mulhres trabalhassem, não era considerado adequado para uma mulher respeitavel ter carreira ou mesmo ser educada. Muitas escolas recusavam-se a admilir mulheres e poucas iam alem da escola primária. Wlas normalmente conheciam pouco ou nada sobre ciência. filosofia ou problemas sociais. 
Como resultado, a enfermagem secular em muitos hospitais era desenvolvida por mulheres de classes inferiores, que eram forçadas a cuidar sem possuir experiencia ou desejo de serem boas enfermeiras. Algumas não viam nada de errado em roubar alimentos dos pacientes.

Um fato novo no entanto vem desencadear um processo de transformação na enfermagem.

Neste mesmo período, houve o ressurgimento das diaconisas, em Kaiserswerth (Alemanha), exatamente 200 anos aposs o início do trabalho de São Vicente de Paula.

O pastor Fliedner e sua esposa reuniram algumas jovens, cuidadosamente escolhidas para cuidar da assistência de um pequeno hospital. Elas recebiam um programa de estudo que incluia o ensino tebrico e prático ministrada por médicos, a farmacologia, e eram submetidas a exames sobre tais assuntos. ( $)$ pastor Fliedner ensinava ética e religião e. sua mulher a enfermagem prática. No hospital, as moças eram divididas por responsabilidades como cozinhar e cuidar do ambiente, lavanderia. cuidado da enfermaria de mulheres e de crianças.

O experimento de Kaiserswerth foi um sucesso. o muitas instituiçôes comecaram a ser desenvolvidas seguindo as regras dos Fliedners.

$\Lambda$ diaconisas passaram a obter grande reputação, pela gentileza e inteligência com que desempenhavam seus trabalhos. Assim grupos de diaconisas eram enviados a outros lugares e ate a outros páses. inclusive a América. () ponto fraco do sistema era o não pagamento do trabalho. $\Lambda$ sra. Fliedner era uma pessoa muito criativa no treinamento das diaconisas. Ela mantinha um diário no qual registrava todas as suas experiências. alem dos princípios e métodos que se mostravam corretos no cuidado. Lste diário jamais foi publicado. o que o uma pena. Este teria sido provavelmente o primeiro livro sobre etica em enfermagem e treinamento prático de enfermejras, escrito por uma mulher. Há razoes para pensar que este material foi usado posteriormente por muitos pastores para o treinamento de enfermeiras.

Esta iniciativa estabeleceu o estaggio para a fundação de um novo siste. ma de enfermagem.

Foi neste cenário que teve início o trabalho de Florence Nightingale. $\Lambda$ sua historia o prova de habilidade de uma mulher para fazer contribuiçoess importantes num ambiente cultural dominado por homens. ('onhecer a sua historia e constatar como uma mulher profundamente educada o preparada foi capaz de atuar para promover e enobrecer o trabalho que escolheu.

Sua firme decisão de fazer alguma coisa por alguém. de entrar para um hospital inglês. foi concretizada em 1851, aos 31 anos de idade. quando 
obteve o consentimento da família para um período de três meses de treinamento em Kaiserswerth com os Fliedners. Em 1852 visitou diversos hospitais na Inglaterra. Irlanda e oultros paises. Em 1853. passou um mês com as irmãs de caridade de Paris, estudando sua organização e disciplina.

Após estas experiências ela publica seu primeiro texto sobre enfermagem que consistia numa análise e comparação dos sistemas de enfermagem na França. Austrália. Itália o Alemanha.

Florence Nightingale pôde demonstrar sua incomum habilidade execuliva em uma clínica e em serviços voluntários em Londres e durante uma epidemia de colera. Suas ideias eram revolucionárias. Foram instaladas campainhas para os paeientes. elevadores que traziam os alimentos para que as enlermeiras não saíssem das enfermarias, alem de abolir todos os testes de roligiosidade para admissão das enfermeiras.

Florence sabia que havia deficiêneia nos hospitais e nos cuidados prestados aos pacientes e queria reforma-los. Após o trabalho desenvolvido durante a guerra da (Crimeia (1854). Florence e suas enfermeiras voltaram com a repulação reluzente.

$\Lambda$ enfermagem não seria mais a mesma. At.e a imagem popular da enfermeira foi transformada. $\Lambda$ enfermeira passou a ser associada a dama da lampada por representiar a figura de Florence no atendimento aos doentes e feridos na guerra.

Durante a guerra. $73 \%$ dos soldades morreram em seis meses por doencass. Motivada por este acontecimento Florenee queria promover reformas. Chegou a conveneer a rainha Victoria. mas, para obter apoio do parlamento inglês precisava de evidencias concretas. Para isto. em 1857. escreveu um relatório sobre a saúde eficiência e administracão hospitalar das forças armadas britânicas. Relatório este de quase uma centena de páginas, repleto de figu ras fotos, tahelas e comparaçoos estatísticas. Tendo como base esse relatório. começaram mudanças no sistema de saúde da Inglaterra..

Ao mesmo tempo que se ocupava com a situação de saúde da populasão. Florence interessava-se tambem pela enfermagem. Seus estudos, observaçoes e reflexões resultaram na publicação de dois livros "Notes on Nursing" em 1859. onde enfatizava o papel do hom cuidado de enfermagem para a recuperação do doenter. "Notes on Hospital". onde mostrava como. atraves de melhores construçoes administração e condiçoes sanitárias poder-so-ia ajudar na cura de doentes.

Utilizando o funde oferecido pela nação britanica como reconhecimento ao seu trabalho na guerra em 1860 . Florence cria comosempre idealizou. uma escola de treinamento para enfermeiras. Sua intenção com a escola. não era treinar enfermeiras para a prática. mas treinálas para irem a outros hospitais e lá. por sua vez. organizarem. ensinarem e lreinarem. 
Esta foi a semente, atraves da qual o mundo de enfermagem existente foi alterado. Todo o sistema vigente de enfermagem sofreu uma revolução com a introdução de mulheres educadas. refinadas e treinadas. amparadas por um emergente conhecimento específico de enfermagem.

\section{$4^{2}$ Fase: " $\Lambda$ Conquista da Identidade"}

Florence Nightingale elevou a enfermagem na opinião pública c mais do que ninguem, foi responsavel pela concretização do conceito de enfermeira treinada. Este sucesso foi devido principalmente à sua determinação, mas tambem em parte ao fato de que suas ideias coincidiam com a emancipacão da mulher. Embora, ela propria, evitasse envolver-se no movimento feminista, insistia que as mulheres tinham o direito de serem educadas.

Ao estabelecer a enfermagem como uma profissão. cla aloriu um grande campo para as mulheres que gradualmente atingiram mais liberdade.

() trabalho de Florence ao fundar sua escola de enfermagem na Inglaterra, tornou-se bastante eonhecido na $\Lambda$ mérica. elá há algum tempo. outras pessoas partilhavam de sua visão de que uma molhor enfermagem poderia ser obtida por mulheres educadas.

Nos Listados Unidos o tralialho educacional de Florence Nightingale e a guerra civil, focalizaram a atenção para a necessidade de enfermeiras o para a importâneia de um sistema educacional no qual pudessem ser preparadas.

Èm 1869 a Associação Médica Americana recomendou que a enfermagem fosse colocada sob o eontrole da medicina. Propondo, ainda que deveria haver uma escola para treinamento de enfermeiras em cada grande hospital. não somente para atender as demandas do hespital, mas também para treinar enfermeiras para cuidarem de lamílias em suas casass.

Estas recomendacões. no entianto. não foram adotadas.

$\Lambda$ ideia de enfermeira treinada vinha gradalivamente sondo sulsstituída pela necessidade de enfermeira profissional que seria formada por um programa educacional bem planejado. eom um corpo especifieo de eonheeimento, diferente do conteúdo da medicina. Hsice conhecimento seria obtido numa instituição educacional. ao invess do uma institução voltada para o serviço.

$\Lambda$ finalização do treinamento resultaria na oblencão de grau academico o um certificado profissional. Este seria o caminho para de uma ve\% a enformagem estabelecer sua posição na sociedade. 
Até o estabelecimento das primeiras escolas formais para enfermeiras, as pessoas envolvidas no cuidado de doentes recebiam aulas ocas ionais de médicos, o que não consistia em instrução organizada, mas informações sim. ples e isoladas para realizar o cuidado aos doentes.

As irmandades católicas dispunham de um preparo mais organizado, restrito aos membros da ordem.

$O$ interesse na educação de enferm agem era grande e culminou com o aparecimento de escolas, em 1873, em Nova York, Boston e New Ilaven, inicialmente baseadas no modelo Nightingale. mas que por força das circunstâncias foram levadas a seguir um caminho diferente.

() sistema de ensino não tinha força, e ainda que as escolas tenham sido criadas independentemente de hospitais, os hospitais descobriram que as escolas poderiam ser criadas para servir as suas necessidades. Assim o cuidado de enfermagem tornou-se o principal produto dispensado pelos hospitais, e a função real das escolas de enfermagem, deixou de ser a educação, para atender ao serviço.

Além disso, nenhuma norma para controle do número de escolas de enfermagem ou de padrões de admissão e graduação foi estabelecido, o que resultou numa proliferação de escolas de enfermagem sob o controle e direção geral do hospital.

Numa época em que o conceito de que na unidade havia força, conceito este seguido pela indústria e grupos sociais e políticos, a enfermagem passa também a desenvolver uma consciência de grupo, o que resultou na formação de organizações oficiais.

Uma das primeiras organizações foi uma associação de enfermeiros graduados (1896) que depois passou a ser denominada Associação Americana de Enfermagem (1911).

As enfermeiras haviam sentido a necessidade de desenvolver sua influência, reconhecendo a urgência de trabalharem coletivamente para controlar e clevar as escolas de enfermagem e prover professores qualificados para o sistema de enfermagem poder sobreviver e crescer.

$\Lambda$ visão de Florence. Nightingale influenciou a identidade da Enfermagem e conseqüentemente o seu ensino, em praticamente todos os continentes. ainda no śćculo 19. No Brasil. a sua influencia teve início na década de 1920 .

A enfermagem deixa o treinamento ocasional para os serviços hospitalares e entra no seculo 20 . com uma identidade estabelecida. resultante de educação baseada em conteúdo específico de enfermagem e fortalecida pelas organizaçōes criadas. que passaram a desenvolver recomendações relevantes aos padrões educacionais e da pratica. 
Em meados de 1800, Florence Nightingale já expressava sua firme convição de que a enfermagem necessitava de conhecimento distinto do conhe. cimento médico.

Em conseqüência da melhor organização do ensino de enfermagem, a literatura de enfermagem passa a se expandir. lla um grande aumento de livros textos e de referência, sendo alguns produzidos pelas enfermeiras, individualmente ou através de suas organizações.

O primeiro livro americano de enfermagem foi publicado em 1885), e em 1930 havia aproximadamente 700 livros para enfermeiras.

As revistas tambem se fizeram necessárias como meios de comunicacão entre as enfermeiras de vários locais. Assim, em 1900 foi editado o primeiro número do "American Journal of Nursing".

Até a década de 50, neste século 20, a prática de enfermagem era baseada em regras, princípios e tradições passados através de educação a senso comum, conseqüentes de anos de experiência.

A enfermagem começa a emergir como ciência no mundo à partir dos anos 50. Em 1952 e publicada uma revista "Nursing Research" especialmente destinada a ser veículo para comunicação dos estudos relacionados à enfermagem.

A pesquisa em enfermagem 6́ nova e antiga ao mesmo tempo. Florence Nightingale foi também a primeira "enfermeira pesquisadora", uma vez que suas reformas na enfermagem foram baseadas em cuidadosas investigaçoòs.

Em 1858, Florence Nightingale foi eleita membro da sociedade real de estatística (Inglaterra) o em 1874. membro honorário da Sociedade Americana de Estatística, por ter sido pioneira no método gráfico de apresentacão de registros hospitalares. tabelas corretas de mortalidade e uma classificação logica de doenças.

Embora a tradição de Nightingale de como fazer e ensinar enfermagem tenha sido transmitida para o mundo. sua abordagem e uso de pesquisa não o foi. $\Lambda$ atmosfera dos ambientes de ensino e de serviço onde prevalecia uma disciplina rígida e obediencia inquestionavel, em nada favoreciam mentes inquiridoras. $\mathrm{Alem}$ disso, estes ambientes não conduziam para a pesquisa e nem eram as enfermeiras preparadas para tais habilidades.

Entretanto, a necessidade para pesquisar foi reconhecida e o caminho para gerar novos conhecimentos para a enfermagem o o cuidado comecou a ser trilhado. 
Apenas na década de 50 , ou seja, quase 90 anos após Florence Nightingale ter apresentado sua definição e teoria de enfermagem, os enfermeiros iniciaram intensos esforços para desenvolver, articular e testar teorias de enfermagem.

O progresso nos estudos e no desenvolvimento de teorias de enfermagem 6. um aspecto significativo na evolução da enfermagem o o fundamento para afirmar.se como disciplina autônoma.

O) desenvolvimento de teorias revelou-se um meio de estabelecer a enfermagem como profissão e 6 inerente ao interesse dos enfermeiros em definir um corpo de conhecimento proprio de enfermagem.

$\Lambda$ produção e a utilização do conhecimento específico. produzido pelos próprios enfermeiros, têm ajudado a definir e direcionar a profissão, a estabelecer a evolução, o caminho a ser percorrido pelo enfermeiro, em sua historia pessoal.

\section{6" Fase: "A Evolução do Enfermeiro"}

Como vimos. a maneira como o conhecimento de enfermagem foi construído como profissão, com identidade estabelecida e que vem realizando significativos progressos em direção à sua alutonomia, uma ve\% que possui um corpo de conhecimento próprio e a cada dia se torna mais completo na capacidade de explicar o fenômeno do cuidar em enfermagem.

Este movimento da enfermagem foi possível porque pessoas, algumas conhecidas por nós, outras anônimas. comprometeram-se ou eram apaixonadas pelo que faziam. Is e devido as suas mentes inquiridoras, motivação e trabalho que resultaram em certos pensamentos a ações, que temos suporte para referirmo-nos hoje, sobre a ciencia da enfermagem.

$\Lambda$ historia revelou o desenvolvimento da profissão como um processo, um constante vir a ser. $\Lambda$ ssim sendo. a enfermagem depende daqueles que a vivem e da maneira como a vivem.

E tal como a enfermagem. o desenvolvimento do profissional pode ser tamben visto como tendo os mesmos quatro elementos: a motivação que nos leva a sentir que este e o caminho que desejamos trilhar. o início na profissão que pode ser caracterizado pelo conhecimento obtido nas escolas de graduação. que nos confere nossa identidade de enfermeiros eo início do trabalho em enfermagem. Quanto a autonomia. esta mais do que as anteriores. está nas mãos de cada profissional, que deverá construí-la para si mesmo. quando aplica conhecimentos no seu cotidiano ou vai alem propondo novas 
maneiras de compreender e agir em enfermagem. (Com isto, o profissional está firmando não somente sua própria autonomia, mas também participando ativamente do processo de crescimento da enfermagem, tal como as primeiras mulheres na historia antiga que agram vivendo plena e intuitivamente o trabalho que desenvolviam, não por obrigação "cientifica". mas principalmente pela sua condição humana que as impelia a aprender, a querer mais, e que nem por isso foi menos importante na compreensão e na construsão da enfermagem.

() reconhecimento da importância de nossas ações pessoais para o desenvolvimento do conhecimento da enfermagem. aconteceráa ao longo da his. toria. naturalmente. Portanto não precisamos nos preocupar com a história que está por vir mas, com a maneira como usamos nossa motivação. com o que fazemos com as questões originadas em nossas mentes inquiridoras e com o quanto desejamos e ousamos partilhar aquilo que sabemos. divulgando nossas experiências pessoais de construção da enfermagem. tornando-a um conhecimento comum.

\section{CONCLUSÃO}

Embora todas as artes requeiram certas qualidades inatas. najo se alinge a perfeição sem treinamento cuidadoso. experiência. reflexão e soloretudo conhecimento.

Somente com a evolução da enfermagem como ciência. o que significa ter um corpo de conhecimento próprio o aplicado. esta arte fara progresso o seráa reconhecida como autônoma.

$\Lambda$ ciêneia da enfermagem o e continuará sendo desenvolvida. como vimos na história, pelos enfermeiros e. cerlamente. a contribuição de cada um de nós para o estabelecim ento desta ciência. são nossas idéias e nossas açoes norteadas tanto por nosso empirismo (sensibilidade) como por nossa ciência (conhecimento).

ANGELO. M. et al. From the empiricism to the science: the evolution of the nursing knowledge. Rev. Esc. Hnf. USP. v.29. n.2. p.211.23. aug. 1995

The aim of this paper is to show the evolution of the nursing knowledge. Some relations with the nursing history are purposed, in order to indicate the ways the people and ideas of today in nursing was influenced by the past. The authors make a correlation between the development of the nursing as profession and of the nurse as profissional.

INITERMS: History of nursing. Nurses role. Education nursing. 


\section{REFERÊNCIAS BIBLIOGRÁFICAS}

BROOKS. J.A.: KLEINE-KRACHT, A.E. Evolution of a definition of nursing Adv. Nurs. Sc., v. 5. n. 4. p. $51-85,1983$

BULLOUGH, V.L.: BULLOUGH. The emergence of modern nursing 2 ed. London. McMillan Co. 1969 .

COLLIERE, M.F. Invisible care and insible women as health care-providers. Int.J. Nurs. Stud. v. 23. n. 2. p. 95-112, 1986

DOLAN. I.A.: FITZPATRICK. M.L.: HERRMANN. E K. Nursing in Society: a historicol perspective. 15 ed Philadelphia. Saunders. 1983.

HAMILTON. D.B. The idea of history and the history of ideas. Image, v. 25, n. 1. p. 45-8. 1993

KIDD.. P.: MORRISON, E.F. The progression of knowledge in nursing: as search for meaning Image, v. 20. n. 4. p. 222.24. 1988.

PEPIN. J.I. Family coring and coring in nursing. Image. v. 24. n. 2. p. 127-31. 1992.

THOMPSON, J.L. Practicd discourse in nursing: going beyond expiricism and historicism. Adv. Nurs. Sc., v. 7. n. 4. p. 59-71. 1985

DOCK. L.L.: STEWART. I.M. A short history of nursing. New York. G.P. Putnam's Sons. 1938 